\title{
Origin of size effect on efficiency of organic photovoltaics
}

\author{
Manor, Assaf; Katz, Eugene A.; Tromholt, Thomas; Hirsch, Baruch; Krebs, Frederik C
}

Published in:

Journal of Applied Physics

Link to article, DOI:

$10.1063 / 1.3567930$

Publication date:

2011

Document Version

Publisher's PDF, also known as Version of record

Link back to DTU Orbit

Citation (APA):

Manor, A., Katz, E. A., Tromholt, T., Hirsch, B., \& Krebs, F. C. (2011). Origin of size effect on efficiency of organic photovoltaics. Journal of Applied Physics, 109(7), 074508. https://doi.org/10.1063/1.3567930

\section{General rights}

Copyright and moral rights for the publications made accessible in the public portal are retained by the authors and/or other copyright owners and it is a condition of accessing publications that users recognise and abide by the legal requirements associated with these rights.

- Users may download and print one copy of any publication from the public portal for the purpose of private study or research.

- You may not further distribute the material or use it for any profit-making activity or commercial gain

- You may freely distribute the URL identifying the publication in the public portal

If you believe that this document breaches copyright please contact us providing details, and we will remove access to the work immediately and investigate your claim 


\title{
Origin of size effect on efficiency of organic photovoltaics
}

\author{
Assaf Manor, ${ }^{1}$ Eugene A. Katz, ${ }^{1,2, a)}$ Thomas Tromholt, ${ }^{3}$ Baruch Hirsch, ${ }^{1}$ \\ and Frederik C. Krebs ${ }^{3}$ \\ ${ }^{1}$ Department of Solar Energy and Environmental Physics, J. Blaustein Institutes for Desert Research, \\ Ben-Gurion University of the Negev, Sede Boker Campus 84990, Israel \\ ${ }^{2}$ The Ilse Katz Institute for Nanoscale Science and Technology, Ben-Gurion University of the Negev, \\ Beer Sheva 84105, Israel \\ ${ }^{3}$ Ris $\phi$ National Laboratory for Sustainable Energy, Technical University of Denmark, Frederiksborgvej 399, \\ DK-4000 Roskilde, Denmark
}

(Received 13 November 2010; accepted 17 February 2011; published online 7 April 2011)

\begin{abstract}
It is widely accepted that efficiency of organic solar cells could be limited by their size. However, the published data on this effect are very limited and none of them includes analysis of light intensity dependence of the key cell parameters. We report such analysis for bulk heterojunction solar cells of various sizes and suggest that the origin of both the size and the light intensity effects should include underlying physical mechanisms other than conventional series resistance dissipation. In particular, we conclude that the distributed nature of the ITO resistance and its influence on the voltage dependence of photocurrent and dark current is the key to understanding size limitation of the organic photovoltaics (OPV) efficiency. Practical methods to overcome this limitation as well as the possibility of producing concentrator OPV cells operating under sunlight concentrations higher than 10 suns are discussed. (c) 2011 American Institute of Physics. [doi:10.1063/1.3567930]
\end{abstract}

\section{INTRODUCTION}

Organic photovoltaics (OPV) has been suggested as an alternative to conventional photovoltaics based on inorganic semiconductor solar cells. The major advantages of OPV include their light weight, mechanical flexibility, and processability (OPV cells may be solvent-processed via common low-cost, high-throughput coating and printing techniques enabling the preparation of large-area, low-cost devices). In particular, intense research is directed toward the development of OPV with a bulk heterojunction (BHJ) where donor-type conjugated polymers (hole conducting) and acceptor-type (electron conducting) fullerenes [or fullerene derivatives, such as [6,6]-phenyl-C61- butyric acid methyl ester (PCBM)] are mixed to form the photoactive layer. $^{1-3}$ The most studied donor/acceptor pair in the $\mathrm{BHJ}$ cells is poly(3-hexylthiophene) (P3HT)/PCBM. ${ }^{4-7}$

Upon illumination, light is absorbed by the conjugated polymer resulting in the formation of a neutral and stable excited state (binding energy $\sim 0.5 \mathrm{eV})^{8}$ on the polymer chain. Free carriers can be generated by exciton dissociation at a donor-acceptor interface, leaving the electron on the acceptor (fullerene in this case) and the hole on the conjugated polymer donor. Efficient charge generation requires, therefore, that the donor and acceptor materials form interpenetrating and continuous networks, "phase separated" on the scale of the exciton diffusion length: $\leq 10 \mathrm{~nm} .{ }^{9}$ Following the exciton dissociation into free carriers, the electrons and holes are conducted through the respective semiconductor moieties (fullerene percolation network for electrons, and

\footnotetext{
a) Author to whom correspondence should be addressed. Electronic mail: keugene@bgu.ac.il.
}

conjugated polymer chains for holes) toward the respective electrodes.

Accordingly, the main difference in charge generation in organic and inorganic solar cells lies in the basic properties of the photogenerated excitations. In organic solids, photogenerated excitations (excitons) are strongly bound and do not spontaneously dissociate into separate charges. The immediate consequence is that light absorption does not necessarily lead to the generation of free carriers and photocurrent becomes voltage dependent. ${ }^{10-15}$

Serious progress has been achieved in the improvement of photovoltaic performance of BHJ solar cells: while the best power conversion efficiency (PCE) reported 8 years ago barely reached values higher than $1 \%,{ }^{3}$ certified efficiencies beyond $6 \%$ and even $8 \%{ }^{16}$ are state of the art today (Table I).

It is widely accepted that OPV efficiency can be limited by the cell area. All of the record efficiencies (Table I) were reported for ultrasmall BHJ OPV cells (with area $\ll 0.4 \mathrm{~cm}^{2}$, a low area limit for the PCE measurements suggested in the recent editorial report ${ }^{24}$ ). However, no systematic attention has been paid on the influence of the OPV cell area (size) on the key photovoltaic parameters of the devices. Experimental $^{25-27}$ and modeling ${ }^{26-29}$ data on this effect are very limited and most of the published papers attributed the reduction of the OPV performance with increasing area to the power dissipation on the cell series resistance $R_{S}$ and in particular to the $R_{s}$ contribution by front electrode of transparent conductive oxide (ITO).

The resistive power losses per unit area $P_{R}$ is given by

$$
P_{R}=\frac{R_{s}}{A} I_{\max }^{2}=\frac{R_{s}}{A}\left(J_{\max } A\right)^{2}=R_{s} A J_{\max }^{2},
$$


TABLE I. Record efficiencies for BHJ OPV.

\begin{tabular}{|c|c|c|c|c|c|c|}
\hline Photoactive layer & Cell area, $\left[\mathrm{cm}^{2}\right]$ & $I_{\mathrm{SC}}\left(\mathrm{mA} \mathrm{cm}{ }^{2}\right)$ & $V_{\mathrm{OC}}(\mathrm{V})$ & $\mathrm{FF}$ & $\operatorname{PCE}(\%)$ & Ref. \\
\hline P3HT/PCBM & 0.148 & 9.5 & 0.63 & 0.68 & 5 & 4 \\
\hline P3HT/PCBM & 0.148 & 11.1 & 0.61 & 0.66 & 5 & 5 \\
\hline P3HT/PCBM & Not mentioned & 11.3 & 0.64 & 0.69 & 5.2 & 6 \\
\hline P3HT/PCBM & 0.19 & 11.1 & 0.65 & 0.54 & 4.9 & 7 \\
\hline PSBTBT/PCBM & 0.12 & 12.7 & 0.68 & 0.55 & 5.1 & 17 \\
\hline PCPDTBT: $\mathrm{C}_{70}-\mathrm{PCBM}$ & 0.17 & 16.2 & 0.62 & 0.55 & 5.5 & 18 \\
\hline PTB4/PCBM & 0.095 & 13.0 & 0.74 & 0.61 & 6.1 & 19 \\
\hline PCDTB: $\mathrm{PC}_{70} \mathrm{BM}$ & 0.127 & 10.593 & 0.88 & 0.64 & $6.0^{\mathrm{a}}$ & 20 \\
\hline$-^{\mathrm{b}}$ & 0.043 & 10.321 & 0.81 & 0.72 & $6.0^{\mathrm{a}}$ & 21 \\
\hline tandem PCDTB:PCBM/P3HT:PC ${ }_{70} \mathrm{BM}$ BHJ & 0.045 & 7.8 & 1.24 & 0.67 & 6.5 & 22 \\
\hline Low band gap polymer $/ \mathrm{PCBM}$ & 0.047 & 13.3 & 0.76 & 0.66 & $6.8^{\mathrm{a}}$ & 3 \\
\hline Low band gap polymer $/ \mathrm{PCBM}$ & 0.047 & & & 0.71 & $7.6^{\mathrm{a}}$ & 23 \\
\hline Low band gap polymer $/ \mathrm{PCBM}$ & Not mentioned & & & & $8.13^{\mathrm{a}}$ & 16 \\
\hline
\end{tabular}

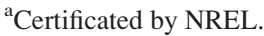

${ }^{\mathrm{b}}$ Composition of the photoactive layer remains proprietary to Plextronics.

${ }^{\mathrm{c}}$ Remains proprietary to Solarmer.

where $A$ is the cell area, $R_{s}$ is series resistance which in turn can be a function of $A, I_{\max }$ and $J_{\max }$ are the cell current and current density in the maximum power point.

Equation (1) shows that $P_{R}$ increases with $J_{\max }$, i.e., with light intensity. Therefore the most powerful tool to investigate the $R_{s}$ effect on the cell performance is measurement of light intensity dependence of the key photovoltaic parameters of solar cells, especially in the regime of high intensities (i.e., above the light intensity at which the cell efficiency peaks). ${ }^{30,31}$ Unfortunately, the authors of Refs. 25-27 measured the cell $I-V$ curves only at one illumination level $\left(C=1 \mathrm{sun}=100 \mathrm{~mW} / \mathrm{cm}^{2}\right)$.

For OPV the intensity dependence of the photovoltaic parameters is still under discussion. To the best of our knowledge, for BHJ OPV it was studied only for $C \leq 1$ sun. ${ }^{13,32,33}$ Ultrasmall bilayer $C_{60} /$ copper phthalocyanine $(\mathrm{CuPc})$ cells were characterized up to 12 suns of simulated illumination. ${ }^{34}$ Recently, ${ }^{35}$ we reported an experimental exploitation of concentrated sunlight for such measurements and demonstrated that the PCE of $1 \mathrm{~cm}^{2}$ P3HT:PCBM BHJ cells peaks at $\sim 1$ sun.

In the present study we extend our experimental approach on the BHJ cells of various areas $(1,0.25$, and 0.04 $\mathrm{cm}^{2}$ ). Perusal of the unexpected results we obtained suggests that the origin of both size and light intensity effects should also include other (than conventional $R_{s}$ dissipation) underlying physical mechanisms. In particular, we conclude that the distributed nature of the ITO resistance and its influence on the voltage dependence of photocurrent (incomplete exciton separation) and dark current is the key to understanding size limitation of the OPV efficiency. This limitation can be fundamental for all kind of excitonic cells ${ }^{15}$ employing front ITO or similar transparent electrode.

\section{EXPERIMENTAL DETAILS}

Using outdoor/indoor test facility based on the fiberoptic/minidish solar concentrator [Figs. 1(a) and 1(b)] $]^{30,31,35}$ we studied BHJ OPV cells of various areas [Fig. 1(c)] layered architecture of "glassIITOIZnOIP3HT:PCBMIPEDOT: PSSIAg" [Fig. 1(d)].

The BHJ OPV devices were prepared in the ambient using a fully roll-to-roll compatible solar cell device preparation. ${ }^{36}$ Commercially available ITO glass substrates with a sheet resistivity of 5-8 $\Omega /$ Square were sonicated in isopropanol followed by washing in demineralized water. Layers of $\mathrm{ZnO}$ nanoparticles, photoactive P3HT:PCBM, and poly(3,4ethylenedioxythiophene): polystyrene sulfonate (PEDOT:PSS) were then subsequently spin coated. All processing steps were conducted in the ambient. An Ag electrode pattern was deposited by thermal evaporation resulting in the three different geometries of the cells. The samples were encapsulated by applying an adhesive plastic foil on the Ag electrode.

The solar cells were mounted in an Al sample holder to ease the physical handling of the samples during the measurements. Additionally, it served as a thermal reservoir, decreasing the heating during the illumination of the cells.

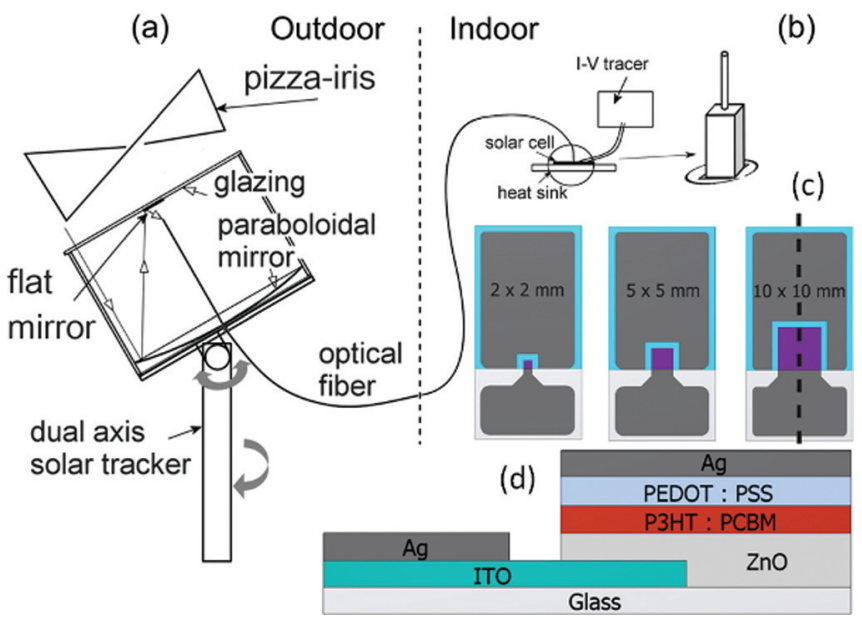

FIG. 1. (Color online) (a) Minidish dual-axis tracking solar concentrator (20 $\mathrm{cm}$ in diameter). (b) Uniform cell irradiation via a kaleidoscope. (c) Top view of cells of various areas. (d) The layer sequence of the inverted P3HT:PCBM BHJ cell (through-glass illumination). The solar cell area is defined as the overlap between the ITO and the Ag electrodes. 


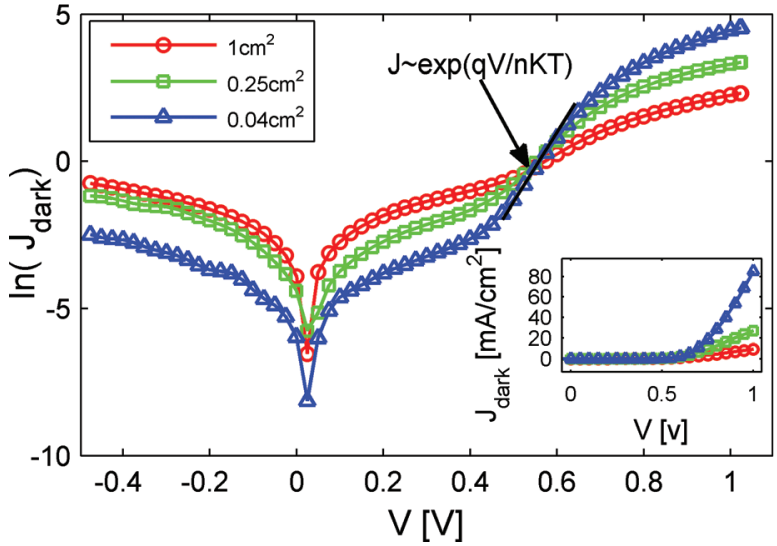

FIG. 2. (Color online) The dark $J-V$ curves for three representative cells with various areas in a semilogarithmic scale. Inset shows the same curves in a linear scale.

Sunlight collected and concentrated outdoors was focused into a transmissive (quartz-core) optical fiber of $1 \mathrm{~mm}$ in diameter and then delivered indoors onto the solar cell being tested [Fig. 1(a)]. Flux uniformity was achieved with a $3 \mathrm{~cm}$ long square cross-section kaleidoscope, matching the size of the cell, placed between distal fiber tip and cell [Fig. 1(b)].

Concentration of sunlight delivered to the cell $C$ was varied gradually from 0.2 to 100 suns with a pizza-slice iris [Fig. 1(a)], and measured pyrometrically. Light current-voltage $I-V$ measurements were made by opening a shutter above the iris and illuminating the cell during $I-V$ tracing only $(<1 \mathrm{~s})$ to avoid excessive degradation and temperature variations. Before this testing, dark $I-V$ curves for every cell were recorded.

$I-V$ curves were recorded with a Keithley 2400 sourcemeter. Light $I-V$ measurements were limited to clear-sky periods, $2 \mathrm{~h}$ around solar noon. The light spectrum on the cell was nearly invariant and close to the AM1.5. ${ }^{37}$
The cell fill factor (FF) and PCE $\eta$ were calculated as

$$
\begin{gathered}
F F=P m / J_{S C} V_{O C}, \\
\eta=P_{m} / P_{i n}=J_{S C} V_{O C} F F / P i n
\end{gathered}
$$

where $J_{\mathrm{SC}}$ and $V_{\mathrm{OC}}$ denote short-circuit current density and open-circuit voltage, respectively. $P_{m}$ and $P_{\text {in }}$ are the maximum electrical output power density and incident light power density.

\section{RESULTS}

Thirteen cells with areas of $1,0.25$, and $0.04 \mathrm{~cm}^{2}$ were investigated. Cells of the same area exhibited similar results. The dark $J-V$ curves for three representative cells of various areas are shown in Fig. 2.

Evolution of the $J-V$ curves of three representative cells recorded under various $C$ are shown in Figs. S1-S3 in supplementary material. ${ }^{38}$

Figure 3 summarizes our data for $J_{\mathrm{SC}}, V_{\mathrm{OC}}, \mathrm{FF}$, and $\eta$ of the representative $\mathrm{BHJ}$ cells of various areas as a function of sunlight concentration $C$.

One can see that the observed trends for all the key parameters of the cells qualitatively reproduce those recently ${ }^{35}$ reported for the $1 \mathrm{~cm}^{2}$ cell of similar device architecture. However, we assumed that for the smaller cells the PCE peak would shift toward higher concentrations due to the corresponding shift of FF (this is the known $R_{s}$ effect in inorganic PV also manifested in the larger negative slope of FF vs $\ln C$ in the high concentration regime). For the inorganic semiconductor concentrator cells, it was demonstrated ${ }^{31}$ for example that the PCE of $1 \mathrm{~mm}^{2}$ cell is maximized at $\sim 1,000$ suns while for a $1 \mathrm{~cm}^{2}$ cell of the same nominal architecture it peaks at $\sim 350$ suns.

Contrary to this expectation we have observed:

(1) Increase in the short-circuit current density with the cell area decrease [this is in evidence for all sunlight (a)

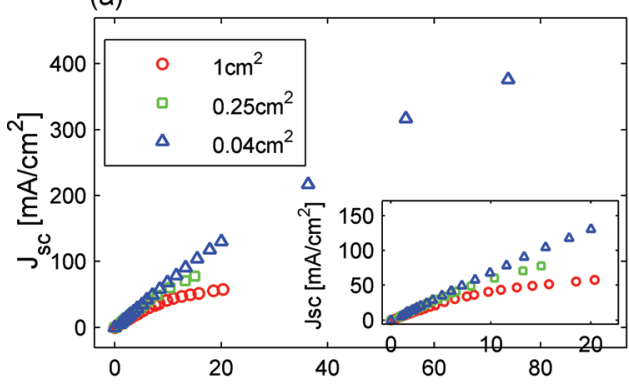

(c) Concentration [suns]

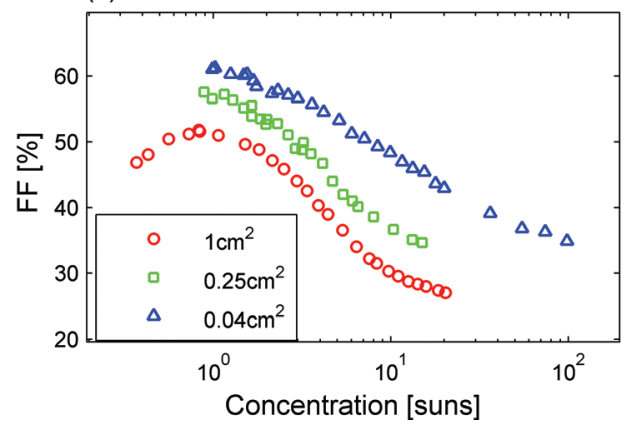

(b)
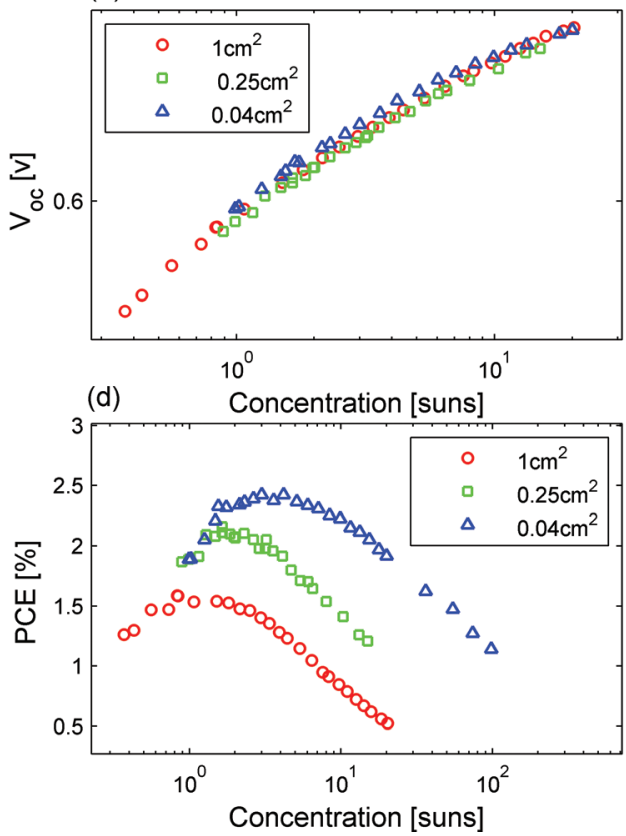

FIG. 3. (Color online) $I_{\mathrm{SC}}(\mathrm{a}), V_{\mathrm{OC}}(\mathrm{b})$, FF (c), and PCE (d) for the representative cells of various areas as a function of sunlight concentration $C$. Inset in (a) shows zoom-in for low concentrations $(0.2 \leq C \leq 20$ suns $)$. 
TABLE II. Analysis of the light intensity dependence of $J_{\mathrm{SC}}$ and comparison of diode quality factors $n$ obtained by three different methods: fitting the curves $V_{\mathrm{OC}} \mathrm{vs} \ln \left(J_{\mathrm{SC}}\right)$; fitting the curves $V_{\mathrm{OC}} \mathrm{vs} \ln \left(J_{\mathrm{ph}} @ V_{\mathrm{OC}}\right)$; fitting the dark $J-V$ curves.

\begin{tabular}{lllllclrr}
\hline \hline Cell area $\left(\mathrm{cm}^{2}\right)$ & $G_{1}$ & $\alpha_{1}$ & $G^{\mathrm{a}}$ & $\alpha_{2}$ & $\alpha_{1}: \alpha_{2}$ border $(\mathrm{suns})$ & $n\left(J_{\mathrm{SC}}\right)$ & $n\left(J_{\mathrm{ph}} @ V_{\mathrm{OC}}\right)$ & $n\left(J_{\text {dark }}\right)$ \\
\hline 1 & 5.03 & 0.99 & 5.33 & 0.66 & 4.5 & 1.5 & 4.7 \\
0.25 & 6.36 & 1 & 5.75 & 0.86 & 6.53 & 1.3 & 3.1 \\
0.04 & 6.77 & 1 & 9.4 & 0.82 & 19.44 & 1.2 & 2.5 \\
\hline \hline
\end{tabular}

${ }^{\mathrm{a}}$ Reference 38 .

concentrations but the effect amplifies with increased concentration-Fig. 3(a)].

(2) Higher FF values of smaller cells for all light intensities (low and high concentration regimes) but no considerable shift of light intensity of the FF peak value with the area decrease [Fig. 3(c)].

(3) Higher PCE values of smaller cells for all light intensities (low and high concentration regimes) [Fig. 3(d)].

(4) Shift (to higher illumination) of the peak PCE light intensity with the area decrease [Fig. 3(d)]. However, it is probably not due to FF shift (as expected) but due to the enhanced $J_{\mathrm{SC}}$ of smaller cells.

The latter is very important, from a practical point of view, for OPV applications in low-cost stationary solar concentrators (at $C \leq 10$ suns). ${ }^{39}$ Indeed, PCE of the smallest cell peaks at $C \sim 3$ suns and exhibit similar values at 1 and 10 suns [Fig. 3(d)].

The observed trends point out that the effect of the cell area is mostly controlled by some mechanism other than $R_{s}$ dissipation. To explain the observed results we will discuss in the following the light intensity dependence for every one of the OPV key parameters $\left(J_{\mathrm{SC}}, V_{\mathrm{OC}} \mathrm{FF}\right)$ as well as for the photocurrent and its voltage dependence.

\section{DISCUSSION}

\section{A. Light intensity dependence of $J_{\mathrm{sc}}$}

It is known that $J_{\mathrm{SC}}$ increases linearly with illumination level $\left(J_{\mathrm{SC}}=G P_{\text {in }}\right)$ for inorganic PV (Ref. 30) and for OPV in the low illumination regime. ${ }^{35}$ For high levels of illumination, the processes of bimolecular recombination ${ }^{10}$ and/or space charge limitation ${ }^{11,12}$ may be intensified and hence the $J_{\mathrm{SC}}$ depends sublinearly on the $P_{\text {in }}$ and $C: J_{\mathrm{SC}}=G \cdot P_{\text {in }}{ }^{\alpha}$, where $\alpha<1$ [for dominant bimolecular recombination $\alpha=0.5$ (Ref. 13) and for dominant space charge limitation $\alpha=0.75] .^{11,12}$

The values $G$ and $\alpha$ are extracted by:

$$
\ln \left(J_{s c}\right)=\ln (G)+\alpha \ln \left(P_{i n}\right) .
$$

By this purpose we replotted the data shown in Fig. 3(a) in a $\log -\log$ scale and then subdivided every curve by two parts: linear $\left(\alpha_{1}\right.$ is very close to 1$)$ and sublinear $\left(\alpha_{2}<1\right)$ (with the curve-fitting coefficient of determination $R^{2}$ higher than 0.99 for all extracted parameters).

Table II shows the results of such analysis

One can see that:

(1) $G_{1}$ and $G_{2}$ values are higher for smaller cells, implying better current extraction (even in the linear regime);

(2) For smaller cells, the linear regime extends further toward higher concentrations (see the column " $\alpha_{1}: \alpha_{2}$ border" with the approximate concentration levels (in suns) where the data starts to deviate from linearity).

\section{B. Light intensity dependence of $V_{\mathrm{OC}}$}

For a $p-n$ junction solar cell:

$$
\begin{gathered}
V_{O C}=(n k T / q)\left[\ln \left(J_{p h} / J_{0}+1\right],\right. \\
J_{p h}=J_{\text {light }}-J_{\text {dark }},
\end{gathered}
$$

where $n$ is a $p-n$ junction quality factor (for an ideal $p-n$ junction cell, $n=1), J_{\mathrm{ph}}$ is photocurrent density, $J_{\text {light }}$ and $J_{\text {dark }}$ are the cell current densities measured under illumination and in the dark, respectively [see Fig. 4(a)].

Since in inorganic PV the voltage-independent $J_{\mathrm{ph}}$ is approximately equal to $J_{\mathrm{SC}}$ and linearly proportional to $c$ :

$$
V_{O C} \approx(n k T / q) \ln \left(J_{S C} / J_{0}\right)=(n k T / q) \ln (c)+\text { const. }
$$

Figure 5(a) shows light intensity dependence of $V_{\mathrm{OC}}$ [shown in Fig. 3(b)] replotted in the scale " $V_{\mathrm{OC}}$ vs $\ln \left(J_{\mathrm{SC}}\right)$ " in order to extract $n$ values according to Eq. (7). One can see that the data can be linearly fitted and the slopes of the linear fits and the corresponding $n$ values decrease with the cell size decrease. Values of $n$ are summarized in Table II. However, (a)

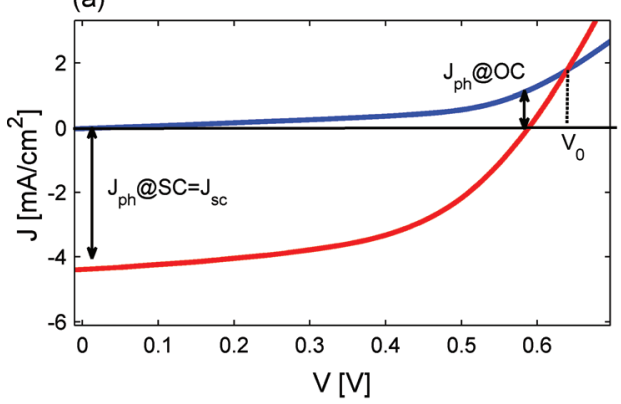

(b)

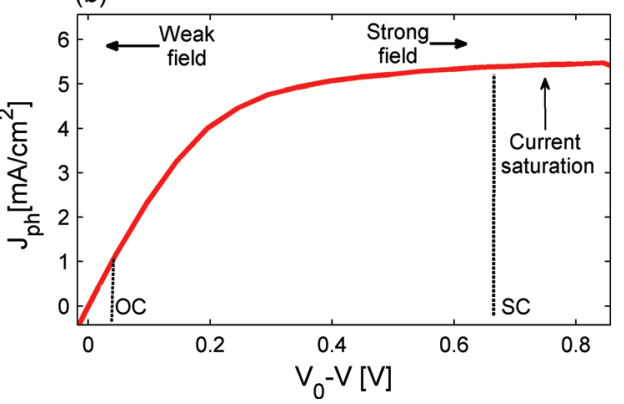

FIG. 4. (Color online) (a) $J-V$ curves of the $1 \mathrm{~cm}^{2}$ cell measured in the dark and under illumination of 1 sun. It is evident that the $J_{\mathrm{ph}}=J_{\text {light }}-J_{\text {dark }}$ measured at the short-circuit conditions $\left(J_{\mathrm{ph}} \approx J_{\mathrm{SC}}\right)$ is much higher that that measured at open circuit $\left(V_{\mathrm{OC}}=0.59 \mathrm{~V}\right)$. Compensation voltage $V_{0}$ at which $J_{\text {light }}=J_{\text {dark }}$ is also indicated $\left(V_{O}=0.64 \mathrm{~V}\right)$. (b) The same curves replotted as $J_{\mathrm{ph}}$ vs $V_{\mathrm{eff}}=V_{0}$ $-V . V_{\text {eff }}$ values for open-circuit (OC) and short-circuit (SC) conditions are indicated. 
(a)

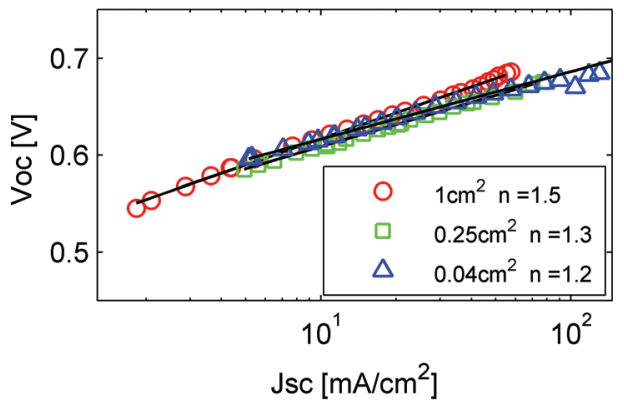

(b)

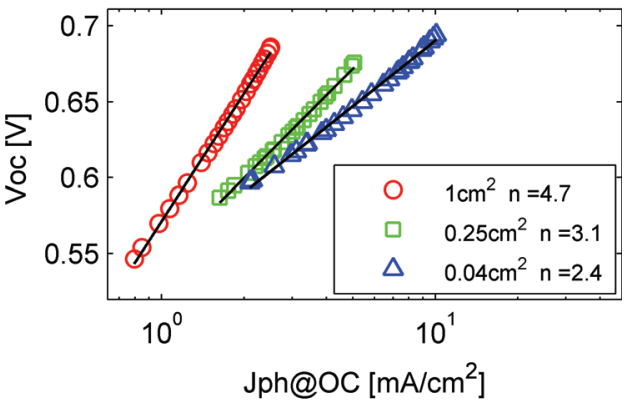

FIG. 5. (Color online) $V_{\mathrm{OC}}$ as a function of Ln $\left(J_{\mathrm{SC}}\right)(\mathrm{a})$ and Ln $\left(J_{\mathrm{ph}} @ V_{\mathrm{OC}}\right)(\mathrm{b})$. these $n$ values contradict with those obtained by the treatment of the dark $J-V$ curves of the same cells (Fig. 2).

Forward-biased dark $J-V$ curves are represented by three successive regimes: ${ }^{40}$ local leakage current, injection current $(J \propto \exp [q V / n k T])$ and space charge limited current $\left(J \propto V^{0.5} / d^{3}\right)$. Thus the semilogarithmic plots of the dark $J-V$ curves (Fig. 2) in the injection current regime $(0.5 \mathrm{~V}<V<0.7 \mathrm{~V}$, marked by an arrow in Fig. 2) has a slope of $q / n k T$. The obtained $n$ values are shown in Table II. One can see that they are considerably higher than those obtained with Eq. (6) and Fig. 5(a).

This contradiction is due to the above-mentioned fact that, because of the excitonic nature of photogeneration in OPV, the photocurrent itself is voltage-dependent. ${ }^{10-15}$ It is clearly seen in Fig. 4(a) and will be discussed in detail in the following (Sec. III C). Accordingly, in order to get more accurate $n$ values we suggest using a semilogarithmic plot of $V_{\mathrm{OC}}$ and $J_{\mathrm{ph}}=J_{\text {light }}-J_{\text {dark }}$ measured at open-circuit conditions, $J_{\mathrm{ph}} @ V_{\mathrm{OC}}$ ) [Fig. 5(b), Table II]. This limits our range of interest to the $V_{\mathrm{OC}}$ voltage range, and therefore to the corresponding $J_{\mathrm{ph}}$ range-which equals exactly $\left(-J_{\text {dark }}\right)$. One can see the better agreement of these data with those obtained by the treatment of the dark $J-V$ curves, as again, smaller cells are characterized by lower $n$ values.

Although a microscopic model for $n$ in BHJ OPV is missing, it is accepted that the ideality factor reflects the "opening behavior" of the diode with the applied voltage with respect to its recombination behavior. ${ }^{41}$ It was also proposed for OPV that $n>2$ could be related to the tunneling effect $^{42}$ (where recombination is intensified by tunneling of charge carriers) or due to reduced mobility in disordered materials where Einstein relation is generalized and can differ from its classical form with $n=1$. $^{43}$ Anyway, a change in the ideality factor could be evidence of a different type of mechanism for the recombination losses at the junctions.

\section{Light intensity dependence FF: Evolution of the shape $J_{\mathrm{ph}}-V$ curves with illumination}

Let us discuss now the field (voltage) dependence of $J_{\mathrm{ph}}$ as a possible underlying mechanism for the shape deterioration of the $J-V$ curves and, as a result, for the light intensity dependence of FF.

Photogeneration of free charge carriers in OPV is preceded by the dissociation of excitons at the donor-acceptor interface. The formation of free electron and hole pairs is a highly field-dependent process, which is reflected in the strong voltage dependence of $J_{\mathrm{ph}}$. To study this dependence it is widely accepted ${ }^{10-15}$ to plot $J_{\mathrm{ph}}=J_{\text {light }}-J_{\text {dark }}$ against the effective applied bias voltage $\left(V_{O}-V\right)$, where $V_{0}$ is the compensation voltage, defined by the voltage at which the $J_{\text {ph }}=0$, i.e., $J_{\text {light }}=J_{\text {dark }}[$ see Fig. 4(b)].

For example in short circuit (SC), $V=0$ and the built-inpotential at the junction $V_{\text {eff }}=V_{0}$ [regime of strong field, $V_{0}=0.64 \mathrm{~V}$ in Fig. 4(b)]. In open-circuit (OC), $V_{\text {eff }}$ $=V_{O}-V_{\text {OC }}[0.05 \mathrm{~V}$ in Fig. $4(\mathrm{~b})]$. In this regime the built-involtage is low and the field across the junction is weak.

Strong voltage dependence of $J_{\mathrm{ph}}$ reduces the FF significantly. ${ }^{44}$ From the shape of the $J_{\mathrm{ph}}$ curve it is possible to characterize the carrier photogeneration and transport in different regimes. Indeed, the behavior of the illuminated $J-V$ response depends on the drift length $\left(L_{D}=\mu \tau E\right.$, where $\mu$ is the mobility, $\tau$ is the lifetime of the charge carriers, and $E$ is the field across the device) of the electrons $(e)$ and holes $(h)$ and the ratio $(b)$ of their drift lengths $\left(b=\mu_{e} \tau_{e} / \mu_{h} \tau_{h}\right)$. For balanced transport $(b \sim 1), J_{\mathrm{ph}}$ varies linearly with $V_{\text {eff }}$ at lower voltage regime and at higher voltage $\left(V_{\text {sat }}\right)$ it saturates to a value $J_{\mathrm{ph}}=q G L$, where $G$ is the generation rate, and $L$ is the thickness of the active layer.

Saturation of $J_{\mathrm{ph}}$ happens when all generated carriers are extracted. If $V_{\text {sat }}>V_{0}$ [SC at Fig. 4(b)], the charge collection efficiency does not approach $100 \%$ even under short-circuit conditions. As $V_{\text {sat }}$ moves closer to $\mathrm{OC}$ it results in the increasing FF and vice versa.

In case of unbalanced transport $(b<1$ or $b>1)$, which is also known as " $\mu \tau$-limited" process, carrier accumulation takes place near both contacts, modifying the field. In an extreme case $(b \ll 1$ or $b \gg 1)$, the slower charge carrier will accumulate near one of the electrodes to a greater extent, leading to buildup of an internal field. When the field in this region becomes equal to the external applied voltage $V$, the current becomes "space charge limited" (SCL). $J_{\mathrm{ph}} \propto$ $V^{0.5}$ in both SCL and $\mu \tau$-limited cases. However, the $J_{\mathrm{ph}}$ varies linearly with $G$, hence with the intensity of illumination $\left(P_{\text {in }}\right.$ or $\left.c\right)$ in $\mu \tau$-limited case and shows a three-quarter dependence on $G$ in the SCL case. The square root dependence on voltage limits the maximum possible $\mathrm{FF}$ to $42 \%$ in the SCL case. ${ }^{11}$

Figure 6 shows the voltage dependence of $J_{\mathrm{ph}}$ in a double logarithmic scale for three cells of different areas and three levels of illumination $(\sim 1, \sim 5$, and $\sim 10$ suns $)$. 
(a)

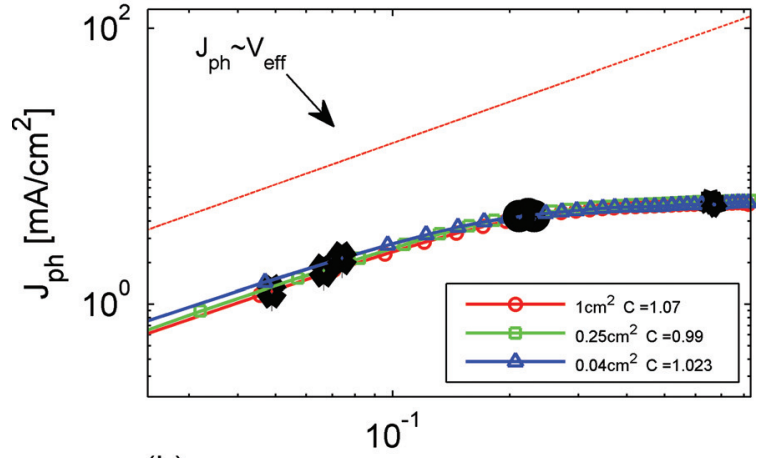

(b)

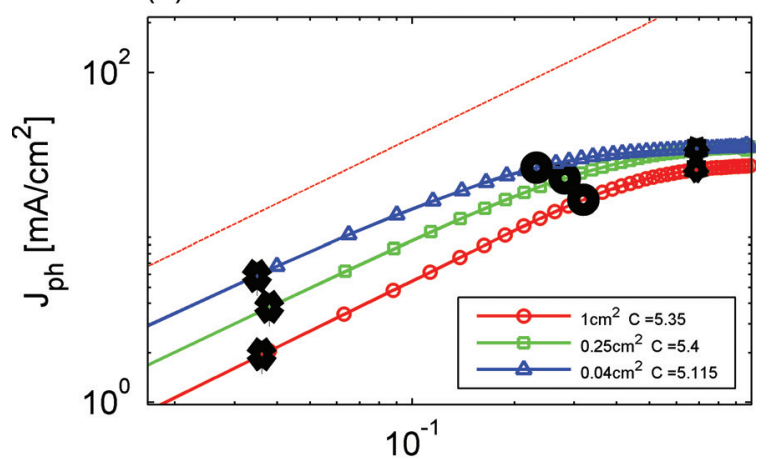

(c)

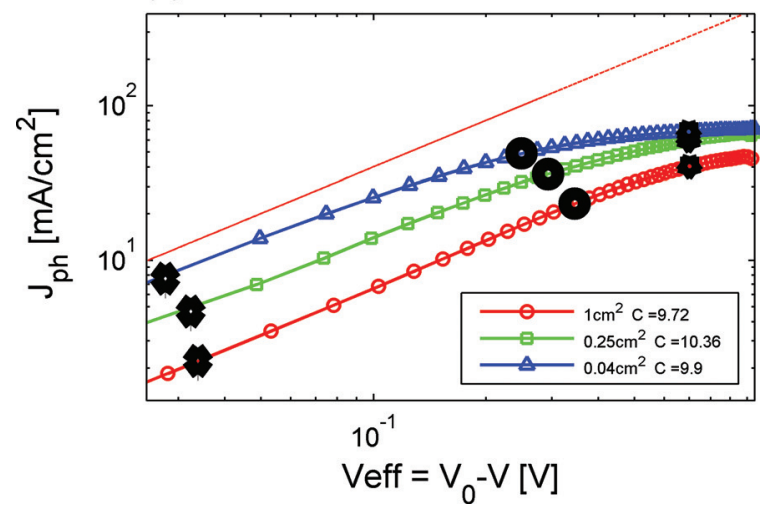

FIG. 6. (Color online) Dependence of $J_{\mathrm{ph}}$ on $V_{\mathrm{eff}}=V_{0}-V$ in a $\log -\log$ scale for three representative cells with various areas measured under $\sim 1$ sun (a), $\sim 5$ suns (b), and $\sim 10$ suns (c). The line marks the slope of 1 for comparison $\left(J_{\mathrm{ph}} \propto V_{\text {eff }}\right)$. Positions of OC, maximum power point (MPP), and SC are indicated by diamonds, circles, and stars, respectively.

One can see from Fig. 6(a) that the photocurrent is approximately equal for the three sizes at $\sim 1$ sun. The saturation values differ a little but the field dependence is similar, meaning that, at this level of illumination, there is no size effect on the photocurrent. The reduced FF value for the larger cell [Fig. 3(c)] should be controlled by a different mechanism (effect of the dark current for example, see the following).

For higher levels of illumination [Figs. 6(b) and 6(c)] the size effect on the photocurrent is evident: the smallest cell reaches saturation regime at lower $V_{\text {eff }}$ than the larger one and the saturation value itself is higher. Such behavior controls both FF (via the location of the MPP on the $J_{\mathrm{ph}}$ curve, as will be discussed in Sec. III C) and $J_{\mathrm{SC}}$ and can explain the size effect on these parameters at high concentrations. (a)

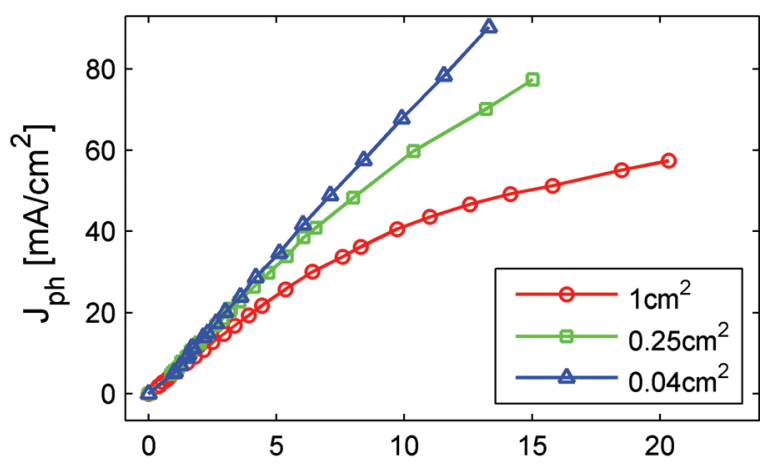

(b)

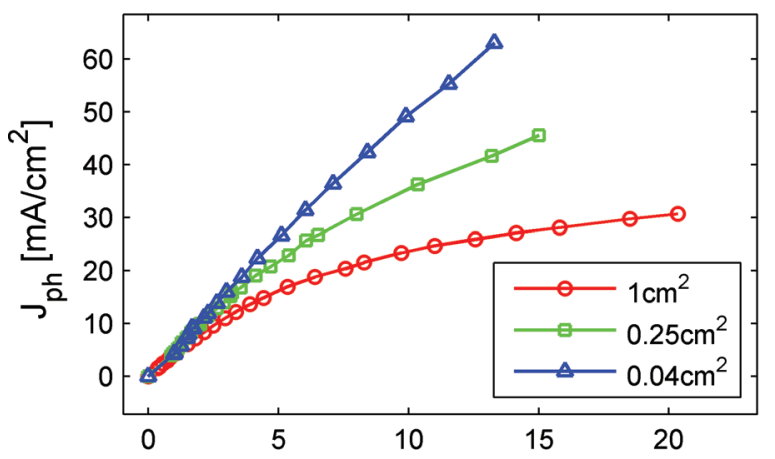

(c)

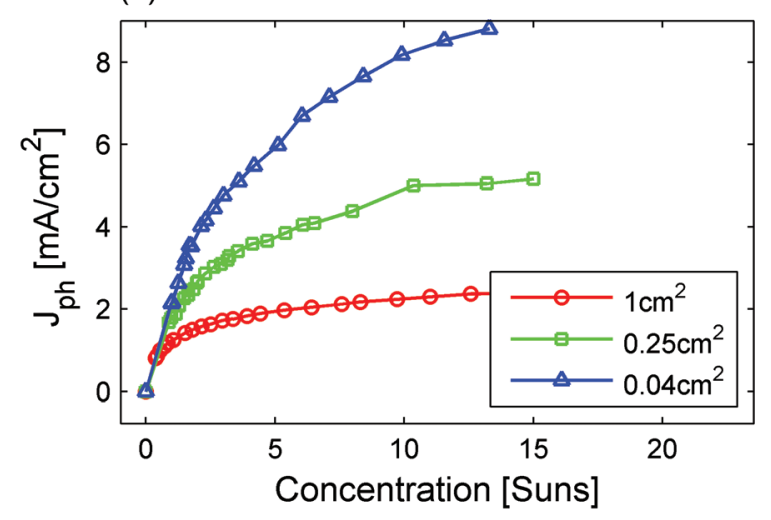

FIG. 7. (Color online) Light intensity dependence of $J_{\mathrm{ph}}$ for the cells of various sizes at SC (a), MPP (b), and OC (c).

One can see however, that for all concentrations, all the cells behave linearly in the low field regime (there is no evidence of SCL effect).

Figure 7 shows the irradiance dependence of $J_{\mathrm{ph}}$ for the cells of various sizes at SC, MPP, and OC conditions.

One can observe that as $V_{\text {eff }}$ decreases (going from SC to $\mathrm{OC}$ ) the nonlinear behavior starts to be exhibited. The first that enters the nonlinear regime is the largest cell-see behavior for SC and MPP [Figs. 7(a) and 7(b)] while at OC all three cells behave nonlinearly at all concentrations [Fig. 7(c)].

Data shown in Fig. 7(a) are in accordance with the results for $J_{\mathrm{SC}}$ [Fig. 3(a)]: for high illumination levels the smaller cell is still in the linear regime of $J_{\mathrm{SC}}-C$, while the larger cells suffer from sublinear behavior.

Thus, we can conclude that the voltage-dependent photocurrent behavior can be responsible for the size effect on 


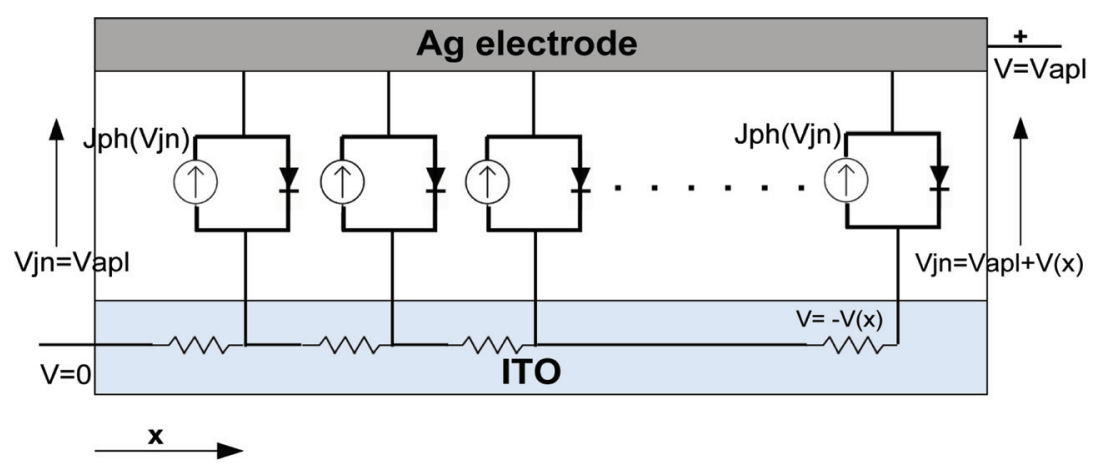

FIG. 8. (Color online) Simplified one-dimensional graphic sketch for a solar cell with distributive series resistance. both $J_{\mathrm{SC}}$ and FF (at least for $C>1$ ). However, two questions still remain open:

(1) Why is the voltage dependence of $J_{\mathrm{ph}}$ stronger for larger cells?

(2) What controls the effect at low illumination levels $(C \leq 1)$ ?

To try and answer the second question let us discuss what controls FF at low light intensities.

Figure S4a in supplementary material ${ }^{38}$ demonstrates voltage dependence for all three currents $\left(J_{\text {dark }}, J_{\text {light }}\right.$ and $\left.J_{\text {ph }}=J_{\text {light }}-J_{\text {dark }}\right)$ measured at 1 sun. Although $J_{\text {ph }}$ for all three cells are similar, the $J_{\text {light }}$ curves exhibit differences (that result in the lower FF for the larger area) and this difference is due to the corresponding difference in the $J_{\text {dark }}$ curves.

However, for $C>1$ (the case of 5 and 10 suns are shown in Figs. S4b-c supplementary material ${ }^{38}$ ) it is evident that the $J_{\text {light }}$ curves (i.e. $J_{\mathrm{SC}}, \mathrm{FF}$, and the corresponding size effects) are completely controlled by $J_{\mathrm{ph}}$ behavior.

\section{On the underlying mechanism of the size effect in OPV cells}

The observed results can be explained on the basis of a model presenting a distributed series resistance of the ITO front electrode in OPV (Refs. 26 and 45) or any other similar electrodes in which current flows parallel to the cell surface (Fig. 8).

The current density $J$ is not constant along the device because the charges that flow from the side distant to the extracting contact experience more series resistance. Simulations (see Fig. 4 in Ref. 44) show that there is a reduction in current density and increase in voltage across the active layer along the dimension $x$ in Fig. 8 .

For each voltage applied to the cell $\left(V_{a}\right)$ there is a voltage drop along the distance from the current-extracting contact (marked by a dash in Fig. 8). This drop causes the increase in voltage across the junction $\left(V_{\text {jn }}\right)$ and the reduction in the current from the distant parts of the cell, caused by the diodes' opening when $V_{\text {jn }}$ increases ${ }^{45}$ and by the voltage dependence of $J_{\text {ph }}$ (Fig. 6). In other words, even if $V_{a}=0$, not all parts of the cell are under SC conditions. Unfortunately, the authors of Ref. 45, assumed in their simulations that photocurrent is voltage independent $\left(J_{\mathrm{ph}}=\right.$ const $)$. Therefore, they only demonstrated a partial effect on FF (current at $V_{a}>0$ ) but did not observe any effect on $J_{\mathrm{SC}}$ (constant current for $V_{a}=0$ in Fig. 5 in Ref. 45). The effect of cell size on FF via the distributive series resistance is well known for inorganic solar cells. However, in OPV it also influences the voltage-dependent $J_{\mathrm{ph}}$ (Figs. 6 and 7). This influence can explain the $J_{\mathrm{SC}}$ behavior [Fig. 3(a)] and provide an additional mechanism for FF degradation. Indeed, if the maximum power point is situated considerably below the saturation regime in the $J_{\mathrm{ph}}-V_{\text {eff }}$ curve [as demonstrated in Figs. 6(b) and $6(c)]$, voltage difference along the cell's active layer (due to the ITO distributive resistance) causes a large decrease in $J_{\mathrm{ph}}$ in the cell areas that are far from the current extracting contact, and, as a result, strong decrease in FF.

The discussed mechanism is dependent on the dimension of the cell (the distance $x$ from the contact). Anyway, the effect should increase for large area cells while the smaller area cells should exhibit better performance.

The phenomenon is fundamental and should take place in any OPV or other excitonic (with voltage-dependent photocurrent) solar cells ${ }^{15}$ with ITO front electrode or any other similar transparent electrodes (graphene ${ }^{46,47}$ and carbon nanotube electrodes, ${ }^{48}$ surface-plasmon enhanced Ag grids ${ }^{49}$ metal nanowire mesh, ${ }^{50}$ etc.) in which current flows parallel to the cell surface. The effect intensifies with illumination level. The illumination level at which the effect starts to be a dominant limiting factor for a certain solar cell may depend on the cell area, resistivity of the transparent electrode, electronic properties of the active layer, etc. We suggest also that this effect can be significant even in the case when the ITO electrode contribution to the $R_{S}$ dissipation of the entire cell is not dominant. However, practical methods to overcome such size limitation and produce efficient largearea OPV cells and modules can be similar to those for reduction of ITO distributive resistance, for example deposition of metal subgrid on the ITO layer. ${ }^{27,51}$ Our results also suggest that by using this technological approach one can produce future concentrator OPV cells operating under sunlight concentrations higher than 10 suns. The latter of course will raise new challenges for OPV stability at these illumination levels. ${ }^{35}$

It is important to add here, that the suggested loss-mechanism analysis also can be relevant in a situation where $J_{\mathrm{ph}}$ is considered to be voltage-independent while recombination losses are charge-density dependent. ${ }^{52}$ Whether the 
additional loss is originated from voltage dependence of photogeneration or enhanced bimolecular recombination, it should depend on the voltage drop along the device front electrode.

Finally, we suggest that the cell's dark current is also affected by the same mechanism. At forward bias the charge carriers are injected into the device and are recombined in the active layer. When the voltage across the ITO layer is not equal, the most distant locations will experience reduced fields and therefore reduced forward currents, thus lowering the quality of the entire diode. It is manifested in the deterioration of the dark $J-V$ curve shape and the effect intensifies with the cell area (as shown in Fig. 2, Table II). Our suggestion is supported by the experimental results on the reduction of electroluminescence intensity with increasing area of ITO transparent electrodes in organic LEDs. ${ }^{53}$

We therefore conclude that the effect of distributed resistance of the transparent electrode can limit the cell FF in high and low illumination regimes in two ways: (1) by the decrease of the photocurrent via its dependence on the applied voltage (high $C$ ); and (2) by the decrease of the diode quality factor and the corresponding deterioration of the dark $J-V$ curve (mainly in lower $C$ regime).

\section{CONCLUSIONS}

1. The $I-V$ curves of as-produced OPV cells of various areas $\left(1,0.25\right.$, and $\left.0.04 \mathrm{~cm}^{2}\right)$ were measured under different sunlight concentrations (from 0.2 to 100 suns) and light intensity dependence of the OPV key parameters $\left(I_{\mathrm{SC}}\right.$, $V_{\text {OC }}$, FF, PCE) was analyzed.

2. We demonstrated experimentally that increase in the cell area results in:

(a) decrease in the short-circuit current density (this is true for all sunlight concentrations but the effect amplifies with the concentration increase);

(b) decrease in FF for all light intensities (low and high concentration regimes);

(c) decrease of the PCE values for all light intensities (low and high concentration regimes) and shift (to higher illumination) of the peak PCE light intensity;

(d) increase of the diode quality factor $n$

3. All the results can be consistently explained by the voltage dependence of photocurrent $J_{\mathrm{ph}}$ (incomplete exciton separation) and the dark current in the presence of significant distributed series resistance of the ITO front electrode or any other similar transparent electrodes in which current flow parallel to the cell surface.

4. The discussed phenomenon is fundamental and should take place in any OPV or other excitonic (with voltagedependent photocurrent) solar cells with highly resistive transparent electrode. The effect intensifies with the illumination level. The light intensity at which the effect starts to be significant for certain solar cells may depend on the cell area, resistivity of the electrodes, electronic properties of the active layer, etc.

5. The results are important for both a basic understanding of the operation of excitonic solar cells and for the practical purpose of producing efficient large-area OPV cells and modules. The possibility of producing concentrator OPV cells operating under sunlight concentrations is higher than 10 suns and is discussed.

\section{ACKNOWLEDGMENTS}

This work was performed, in part, in the framework of the "Largecells" project that received funding from the European Commission's Seventh Framework Programme (FP7/ 2007-2013) under Grant Agreement No. 261936." T.T. and F.C.K. thank the Danish Strategic Research Council (210407-0022) and EUDP (j. nr. 64009-0050) for financial support. E.A.K. acknowledges financial support by the FIRST Focal Initiatives in Science and Technology foundation of the Israel Science Foundation (grant no. 1004/07).

${ }^{1}$ C. J. Brabec, N. S. Sariciftci, and J. C. Hummelen, Adv. Funct. Mater. 11, 15 (2001).

${ }^{2}$ M. Helgesen, R. Søndergaard, and F. C. Krebs, J. Mater. Chem. 20, 36 (2010).

${ }^{3}$ C. J. Brabec, S. Gowrisanker, J. J. M. Halls, D. Laird, S. Jia, and S. P. Williams, Adv. Mater. 22, 3839 (2010).

${ }^{4}$ W. Ma, C. Yang, X. Gong, K. Lee, and A. J. Heeger, Adv. Funct. Mater. 15, 1617 (2005).

${ }^{5}$ J. Y. Kim, S. H. Kim, H.-H. Lee, K. Lee, W. Ma, X. Gong, and A. J. Heeger, Adv. Mater. 18, 572 (2006).

${ }^{6}$ M. D. Irwin, D. B. Buchholz, A. W. Hains, R. P. H. Chang, and T. J. Marks, PNAS 105, 2783 (2008).

${ }^{7}$ M. Reyes-Reyes, K. Kim, and D. L. Carroll, Appl. Phys. Lett. 87, 083506 (2005).

${ }^{8}$ V. I. Arkhipov and H. Bassler, Phys.Status Solidi A 201, 1152 (2004).

${ }^{9}$ J. J. M. Halls, K. P. R. H. Friend, S. C. Moratti, and A. B. Holmes, Appl. Phys. Lett. 68, 3120 (1996).

${ }^{10}$ L. J. A. Koster, V. D. Mihailetchi, and P. W. M. Blom, Appl. Phys. Lett. 88, 052104 (2006).

${ }^{11}$ V. D. Mihailetchi, J. Wildeman, and P. W. M. Blom, Phys. Rev. Lett. 94, 126602 (2005).

${ }^{12}$ V. D. Mihailetchi, H. Xie, B. de Boer, L. J. A. Koster, and P. W. M. Blom, Adv. Funct. Mater. 16, 699 (2006).

${ }^{13}$ J. K. J. van Duren, X. Yang, J. Loos, C. W. T. Bulle-Lieuwma, A. B. Sieval, J. C. Hummelen, and R. A. Janssen, Adv. Funct. Mater. 14, 425 (2004).

${ }^{14}$ P. W. M. Blom, V. D. Mihailetchi, L. J. A. Koster, and D. E. Markov, Adv. Mater. 19, 1551 (2007).

${ }^{15}$ B. A. Gregg and M. C. Hanna, J. Appl. Phys. 93, 3605 (2003).

${ }^{16}$ See http://www.pv-tech.org/news/(last accessed July 2010).

${ }^{17}$ J. Hou, H.-Y. Chen, S. Zhang, G. Li, and Y. Yang, J. Am. Chem. Soc. 130, 16144 (2008).

${ }^{18}$ J. Peet, J. Y. Kim, N. E. Coates, W. L. Ma, D. Moses, A. J. Heeger, and G. C. Bazan, Nature Mater. 6, 497 (2007).

${ }^{19}$ Y. Liang, D. Feng, Y. Wu, S. Tsai, G. Li, C. Ray, and L. Yu, J. Am. Chem. Soc. 131, 7792 (2009).

${ }^{20}$ S. H. Park, A. Roy, S. Beaupré, S. Cho, N. Coates, J. S. Moon, D. Moses, M. Leclerc, K. Lee, and A. J. Heeger, Nat. Photonics 3, 297 (2009).

${ }^{21}$ R. Tipnis and D. Laird, "High efficiency solar cells," SPIE Newsroom Website, December 2008, http://spie.org/x31682.xml?ArticleID=x31682 (last accessed December 2008).

${ }^{22}$ J. Y. Kim, K. Lee, N. E. Coates, D. Moses, T.-Q. Nguyen, M. Dante, and A. J. Heeger, Science 317, 222 (2007)

${ }^{23}$ See http://www.pv-tech.org/news/(last accessed December 2009).

${ }^{24}$ G. P. Smestad, F. C. Krebs, C. M. Lampert, C. G. Granqvist, K. L. Chopra, X. Mathew, and H. Takakura, Sol. Energy Mater. Sol. Cells 92, 371 (2008).

${ }^{25}$ D. Gupta, M. Bag, and K. S. Narayan, Appl. Phys. Lett. 93, 163301 (2008).

${ }^{26}$ A. K. Pandey, J. M. Nunzi, B. Ratier, and A. Moliton, Phys. Lett. A 372, 1333 (2008).

${ }^{27}$ S. Choi, W. J. Potscavage, and B. Kippelen, J. Appl. Phys. 106, 054507 (2009). 
${ }^{28}$ C. Lungenschmied, G. Dennler, H. Neugebauer, S. N. Sariciftci, M. Glatthaar, T. Meyer, and A. Meyer, Sol. Energy Mater. Sol. Cells 91, 379 (2007).

${ }^{29}$ J. D. Servaites, S. Yeganeh, T. J. Marks, and M. A. Ratner, Adv. Funct. Mater. 20, 97 (2010).

${ }^{30}$ E. A. Katz, J. M. Gordon, W. Tassew, and D. Feuermann, J. Appl. Phys. 100, 044514 (2006)

${ }^{31}$ O. Korech, B. Hirsch, E. A. Katz, and J. M. Gordon, Appl. Phys. Lett. 91, 064101 (2007).

${ }^{32}$ I. Riedel, J. Parisi, V. Dyakonov, L. Lutsen, D. Vanderzande, and J. C. Humme, Adv. Funct. Mater. 14, 38 (2004).

${ }^{33}$ L. J. A. Koster, V. D. Mihailetchi, R. Ramaker, and P. W. M. Blom, Appl. Phys. Lett. 86, 123509 (2005).

${ }^{34}$ J. Xue, S. Uchida, B. P. Rand, and S. R. Forrest, Appl. Phys. Lett. 84, 3013 (2004).

${ }^{35}$ T. Tromholt, E. A. Katz, B. Hirsch, A. Vossier, and F. C. Krebs Appl. Phys. Lett. 96, 073501 (2010).

${ }^{36}$ F. C. Krebs, S. A. Gevorgyan, and J. Alstrup, J. Mater. Chem. 19, 5442 (2009).

${ }^{37}$ J. M. Gordon, E. A. Katz, D. Feuermann, and M. Huleihil, Appl. Phys. Lett. 84, 3642 (2004).

${ }^{38}$ See supplementary material at http://dx.doi.org/10.1063/1.3567930 for a brief discussion of the material.

${ }^{39}$ T. Uematsu, Y. Yazawa, T. Joge, and S. Kokunai, Sol. Energy Mater. Sol. Cells 67, 425 (2001).
${ }^{40}$ A. Moliton and J.-M. Nunzi, Polym. Int. 55, 583 (2006).

${ }^{41}$ C. Waldauf, M. C. Scharber, P. Schilinsky, J. A. Hauch, and C. J. Brabec, J. Appl. Phys. 99, 104503 (2006).

${ }^{42}$ A. Kumar, R. Devine, C. Mayberry, B. Lei, G. Li, and Y. Yang. Adv. Funct. Mater. 20, 2729 (2010).

${ }^{43}$ Y. Roichman and N. Tessler, Appl. Phys. Lett. 80, 1948 (2002).

${ }^{44}$ D. Gupta, S. Mukhopadhyay, and K. S. Narayan, Sol. Energy Mater. Sol. Cells 94, 1309 (2010).

${ }^{45}$ M. W Denhoff and N. Drolet, Sol. Energy Mater. Sol. Cells 93, 1499 (2009).

${ }^{46}$ S. S. Li, K.H. Tu, C. C. Lin, C. W. Chen, and M. Chhowalla, ACS Nano 4 , 3169 (2010).

${ }^{47}$ L. G. De Arco, Y. Zhang, C. W. Schlenker, K. Ryu, M. E. Thompson, and C. W. Zhou, ACS Nano. 5, 2865 (2010).

${ }^{48}$ R. Ulbricht, S. B. Lee, X. M. Jiang, K. Inoue, M. Zhang, S. L. Fang, R. H. Baughman, and A. A. Zakhidov, Energy Mater. Sol. Cells 91, 416 (2007).

${ }^{49}$ T. H. Reilly III, J. van de Lagemaat, R. C. Tenent, A. J. Morfa, and K. L. Rowlen, Appl. Phys. Lett. 92, 243304 (2008).

${ }^{50}$ J.-Y. Lee, S. T. Connor, Y. Cui, and P. Peumans, Nano Letters 8, 689 (2008)

${ }^{51}$ S.-Y. Park, W.-I. Jeong, D.-G. Kim, J.-K. Kim, D. C. Lim, J. H. Kim, J.-J. Kim, and J.-W. Kang, Appl. Phys. Lett. 96, 173301 (2010).

${ }^{52}$ C. G. Shuttle, R. Hamilton, B. C. O'Regan, J. Nelson, and J. R. Durrant, Proceedings of the National Academy Sciences 107, 16448 (2010).

${ }^{53}$ C. Pillego, M. Mazzeo, M. Salemo, and G. Gigli, Appl. Phys. Lett. 89, 103514 (2006). 